\title{
What keeps female problematic internet users busy online?
}

\author{
Claire Piguet • André Berchtold • Christina Akre • \\ Joan-Carles Suris
}

Received: 25 September 2014 / Revised: 16 December 2014 / Accepted: 10 February 2015 / Published online: 7 March 2015

(C) Springer-Verlag Berlin Heidelberg 2015

\begin{abstract}
While problematic Internet use is recognized to be predominant among male adolescents, a female trend is gradually becoming apparent. Our study aimed at investigating the characteristics of female Internet users and distinguishing between the online activities of problematic and regular Internet users' on school days. Data were retrieved from a crosssectional survey of a representative sample of 3067 8th graders in the canton of Vaud, Switzerland, that completed an online questionnaire in 2012. Only females were included. Based on the Internet addiction test, the sample was divided into regular (RUs) (IAT $<50, n=1339$ ) and problematic users (PIUs) (IAT $\geq 50, n=201$ ). Groups were compared regarding sociodemographic variables, online activities, devices used to access the Internet, substance use, and physical activity. Significant variables were included in a backward logistic regression. At the multivariate level, PIUs were more prone to spend time online for leisure activities (odds ratio [OR] 2.38) and to access the Internet through a smartphone (OR 1.79) or tablet (OR 1.84). PIUs were less likely to be physically active (OR 0.86 ) and more likely to present poor emotional well-being (OR 2.67) and to smoke (OR 1.88).

Conclusion: A sizeable percentage of female adolescents are problematic Internet users. When performing a
\end{abstract}

Communicated by Jaan Toelen

C. Piguet $\cdot$ C. Akre $\cdot$ J.-C. Suris $(\bowtie)$

Research Group on Adolescent Health (GRSA), Institute of Social and Preventive Medicine (IUMSP), Lausanne University Hospital,

Route de la Corniche 10, 1010 Lausanne, Switzerland

e-mail: joan-carles.suris@chuv.ch

A. Berchtold

Institute of Social Sciences, University of Lausanne,

Lausanne, Switzerland

A. Berchtold

LIVES, University of Lausanne, Lausanne, Switzerland comprehensive biopsychosocial assessment, teenagers owning numerous devices to access the Internet, presenting other health-compromising behaviors or poor emotional wellbeing should be specifically targeted.

What is Known:

- Problematic Internet use has been found to be predominant among males.

- Specific online activities have been identified as being addictive for young men and women differently.

- Problematic Internet use is known to impact in several ways the general health and daily functioning of teenagers.

What is New:

- A sizeable percentage of female adolescents are problematic Internet users.

- Tobacco use, poor well-being, as well as compact devices to access the Internet are positively related to problematic Internet use.

- In addition to their special interest in online social and communicational activities, female problematic Internet users also reported more online gambling.

Keywords Internet $\cdot$ Female adolescents $\cdot$ Internet addiction Online activities
Abbreviations
IAT Internet addiction test
PIUs Problematic Internet users
RUs Regular Internet users

\section{Introduction}

Due to the expanding online connectivity, excessive Internet use among youth has received increased research attention. Adolescents and young people seem at great risk to fall for the potential addictive properties of Internet, given their flexible schedules and academic incitation [6, 23, 7, 39, 9]. It is 
argued that it is not the medium (i.e., Internet) which is addictive but rather specific online activities such as social networking sites, chatting, or online gaming [6, 40, 41]. Indeed, online socialization with peers, which fits particularly to adolescents' developmental needs, has become increasingly popular and can play a significant role in the addictive nature of Internet applications [39, 24, 40].

The literature highlights higher rates of problematic Internet use among males; male gender is considered to be in itself a risk factor for Internet addiction [21, 7, 26, 35]. Then, several authors have been concerned about a female prevalence among excessive Internet users [6, 34, 24, 27]. Leung [27] has found that Internet addicts tend to be highly educated female students who are more likely to reveal and disclose their feelings and emotions on the Internet. Durkee et al. [6] have highlighted a feminine predominance in maladaptive and pathological Internet use in five European countries. Derbyshire et al. [5] have taken a closer look at this female trend which they related to the increasing number of online social activities.

To our knowledge, research focusing exclusively on what female students do online is scarce. Moreover, previous studies on Internet use have failed to exhaustively differentiate between types [33,35] or contexts of use (school days vs. weekends) [6, 7, 42, 37, 29]. While the rate of problematic Internet use among young females seems to increase, little is known about young women who report a problematic use of the Internet $[26,27]$. The objectives of this study were therefore to examine the characteristics of female Internet users and to understand the differences between problematic Internet users' (PIUs) and regular Internet users' (RUs) online activities on school days.

\section{Material and methods}

Data were obtained from the ado@internet.ch survey, a longitudinal study of a representative sample of 35 schools in the canton of Vaud, in the French-speaking part of Switzerland. Only cross-sectional baseline data are discussed here. From 23 April to 4 July 2012 (spring quarter in Swiss schools), 3367 8th graders were invited to participate in the study. All participants were assured that the survey was anonymous and voluntary. Among them, 230 were not attending school the day the questionnaire was administered, 60 refused to participate, and 10 did not correctly respond and were therefore removed. The final sample consisted of 3067 youths, from which only female respondents were included in the analysis $(n=1549)$. The questionnaire consisted of 51 questions and was filled in online in the school's computer science room.
Measures

Based on the French version of the Internet addiction test (IAT) [16], we divided our sample into regular users (RUs) (IAT $<50, n=1339)$ and problematic users (PIUs) (IAT $\geq 50$, $n=201)$ as previously described $[26,36]$. The scale consists of 20 items (such as "Do you feel that you stay online longer than you intend?" or "Do you choose to spend more time online over going out with others?") with responses ranging from 0 (never) to 5 (always). The internal consistency (Cronbach's alpha) of IAT items for the current study was 0.89 .

Concerning activities performed on the Internet, we analyzed two sets of online activities on school days. The first ones were activities devoted to leisure: playing online games with or without money, using social networking sites, listening/downloading music or movies, watching video clips, participating in discussions, and other. The second set of activities was devoted to work or study: using search engines (such as Google ${ }^{\circledR}$ ), using online encyclopedia (such as Wikipedia), reading online newspapers, sending school-/ work- related e-mails, visiting the school website, and other. Four response options were available for each question: never, rarely, often, and very often. These variables were subsequently dichotomized into rarely (never, rarely) and often (often, very often).

Internet use was assessed by asking how much of their Internet time was devoted to school/work or leisure on school days with five response options: most of the time, more than half of the time, about the same time, less than half of the time, and almost no time. Out of the collected data, three categories referring to the main online activity were defined: for schoolwork mainly, similarly for both, and for leisure mainly. Additionally, we also controlled for usual devices to access the Internet with six different options: console, computer, smartphone, tablet, television, and other. To identify what computer was used by the respondents, we asked if they generally used a family computer or a computer shared with their siblings or if they owned a computer.

The co-variables included demographic data which consisted of sex, age, nationality (Swiss born/other), family structure (parents together/other), and residence (rural/ urban). Physical activity was defined by the number of days per week performing a physical activity lasting at least $60 \mathrm{~min}$. Participants were inquired if they smoked (current smoker/other), misused alcohol (at least one episode of drunkenness in the past 30 days), and used cannabis or illegal substances in the last 30 days. To measure emotional well-being, we used the World Health Organization Five Well-Being Index (WHO-5), with a score below 13 indicating poor well-being [4]. 
Data analysis

At first, we performed a bivariate analysis comparing the two groups of Internet users for each variable. Female users who reported not owning a personal or family-shared computer or any other device to connect to the Internet (such as a tablet or smartphone) were removed from the analysis $(n=9)$. All statistically significant variables at the bivariate level were then entered in a backward logistic regression with regular Internet users being the reference category. Results are shown as adjusted odd ratios (aOR) with $95 \%$ confidence intervals.

Finally, we ran a log-linear model to investigate the associations among statistically significant variables. All calculations were undertaken using STATA 13.0 (StataCorp, College Station, TX) except for the log-linear model for which we used the $\mathrm{R}$ environment. Approbation from the Ethics Committee of the canton of Vaud was obtained.

\section{Results}

Among the 1540 female users, 201 (13\%) were identified as problematic Internet users (PIUs). At the bivariate level, PIUs were less likely to have both parents living together and to be physically active. PIUs reported having a poorer emotional well-being than regular users (RUs), as well as higher substance use prevalence rates (Table 1). As seen in Table 2, PIUs were more prone to own a personal computer and to report spending their online time on school days mostly doing leisure activities. They would more frequently download/ listen to music, visit social networking sites, and watch videos compared to RUs and less likely to use online encyclopedias for study-related tasks.

Table 1 Characteristics of regular and problematic Internet users

\begin{tabular}{llll}
\hline Variable & $\begin{array}{l}\text { Regular users } \\
(N=1339)\end{array}$ & $\begin{array}{l}\text { Problematic users } \\
(N=201)\end{array}$ & $\begin{array}{l}P \\
\text { value }\end{array}$ \\
\hline Mean age (years) & 14.21 & 14.30 & 0.092 \\
Emotional well-being (poor) & $16.18 \%$ & $37.62 \%$ & $<0.001$ \\
$\begin{array}{l}\text { Nationality (Swiss born) } \\
\text { Family structure (parents }\end{array}$ & $85.70 \%$ & $84 \%$ & 0.52 \\
$\quad 68.97 \%$ & $61.39 \%$ & $<0.05$ \\
$\quad \begin{array}{l}\text { Regether) } \\
\text { 60-midence (rural) }\end{array}$ & $52.20 \%$ & $51.74 \%$ & 0.90 \\
$\quad$ (mean days) & 2.88 & 2.37 & $<0.001$ \\
$\begin{array}{l}\text { Substance use } \\
\text { Current smoking }\end{array}$ & $13.61 \%$ & $32.25 \%$ & $<0.01$ \\
$\quad \begin{array}{l}\text { Alcohol misuse (30 days) } \\
\quad 7.60 \%\end{array}$ & $16.70 \%$ & $<0.01$ \\
$\quad \begin{array}{l}\text { Cannabis use (30 days) } \\
\quad 6.10 \%\end{array}$ & $14.90 \%$ & $<0.01$ \\
$\quad$ Illegal substance use & $1.10 \%$ & $6.34 \%$ & $<0.01$ \\
$\quad(30$ days) & & & \\
\hline
\end{tabular}

Table 2 Internet use across the two groups

\begin{tabular}{|c|c|c|c|}
\hline Variable & $\begin{array}{l}\text { Regular users } \\
(N=1339)\end{array}$ & $\begin{array}{l}\text { Problematic users } \\
(N=201)\end{array}$ & $\begin{array}{l}P \\
\text { value }\end{array}$ \\
\hline \multicolumn{4}{|l|}{ Computer owning } \\
\hline Family computer & $36.30 \%$ & $21.39 \%$ & \multirow[t]{3}{*}{$<0.001$} \\
\hline $\begin{array}{l}\text { Computer shared with } \\
\text { siblings }\end{array}$ & $12.55 \%$ & $11.44 \%$ & \\
\hline $\begin{array}{l}\text { Own personal } \\
\text { computer }\end{array}$ & $51.16 \%$ & $67.16 \%$ & \\
\hline \multicolumn{4}{|c|}{ Devices to access the Internet } \\
\hline Console & $13.16 \%$ & $18.73 \%$ & $<0.05$ \\
\hline Computer & $93.41 \%$ & $96.71 \%$ & 0.084 \\
\hline Smartphone & $65.99 \%$ & $81.35 \%$ & $<0.001$ \\
\hline Tablet & $31.66 \%$ & $42.31 \%$ & $<0.01$ \\
\hline Television & $22.50 \%$ & $33.56 \%$ & $<0.01$ \\
\hline Other & $3.16 \%$ & $5.84 \%$ & 0.062 \\
\hline \multicolumn{4}{|c|}{ Main Internet use patterns } \\
\hline For leisure mainly & $63.10 \%$ & $83.66 \%$ & $<0.01$ \\
\hline Similarly for both & $17.22 \%$ & $10.89 \%$ & $<0.01$ \\
\hline For work mainly & $19.67 \%$ & $5.45 \%$ & $<0.01$ \\
\hline \multicolumn{4}{|c|}{ Leisure activities on school days (often) } \\
\hline $\begin{array}{l}\text { Online games } \\
\text { (without money) }\end{array}$ & $14.62 \%$ & $24.26 \%$ & $<0.01$ \\
\hline Online gambling & $0.80 \%$ & $4.46 \%$ & $<0.01$ \\
\hline $\begin{array}{l}\text { Social networking } \\
\text { sites }\end{array}$ & $77.88 \%$ & $92.57 \%$ & $<0.01$ \\
\hline $\begin{array}{l}\text { Download/listen to } \\
\text { music }\end{array}$ & $83.52 \%$ & $93.07 \%$ & $<0.01$ \\
\hline $\begin{array}{l}\text { Download/watch } \\
\text { movies }\end{array}$ & $45.14 \%$ & $65.35 \%$ & $<0.01$ \\
\hline Watch videos & $80.18 \%$ & $92.57 \%$ & $<0.01$ \\
\hline $\begin{array}{l}\text { Participation in online } \\
\text { discussions }\end{array}$ & $47.96 \%$ & $70.30 \%$ & $<0.01$ \\
\hline Other activities & $25.76 \%$ & $44.55 \%$ & $<0.01$ \\
\hline \multicolumn{4}{|c|}{ Work/study activities on school days (often) } \\
\hline Search engines & $91.09 \%$ & $89.11 \%$ & 0.363 \\
\hline Online encyclopedias & $68.08 \%$ & $57.43 \%$ & $<0.01$ \\
\hline Online newspapers & $10.10 \%$ & $8.42 \%$ & 0.455 \\
\hline $\begin{array}{l}\text { Communication with } \\
\text { someone }\end{array}$ & $36.02 \%$ & $38.61 \%$ & 0.475 \\
\hline School website & $7 \%$ & $9.41 \%$ & 0.171 \\
\hline Other activities & $31.63 \%$ & $32.67 \%$ & 0.766 \\
\hline
\end{tabular}

In the backward regression, 14 steps were performed and significant variables are presented in Table 3. PIUs reported a poorer emotional well-being and were more than twice more likely to spend time online mainly for leisure. PIUs owned more compact devices to access the Internet, notably smartphones and tablets, and reported a greater use of social networking sites and participation in online discussions as well as online games and gambling. PIUs were less inclined to use online encyclopedias for study-related tasks and to be physically active. Moreover, we found a significant 
Table 3 Multivariate analysis (backward logistic regression) using female regular Internet users as the reference group

\begin{tabular}{|c|c|c|}
\hline Internet addiction group & $\begin{array}{l}\text { Adjusted odds ratio } \\
\text { (CI) }\end{array}$ & $P$ value \\
\hline Emotional well-being (poor) & $2.67(1.86: 3.83)$ & $<0.001$ \\
\hline 60-min physical activity (mean days) & $0.869(0.78: 0.96)$ & $<0.01$ \\
\hline \multicolumn{3}{|l|}{ Devices to access the Internet } \\
\hline Computer & Reference category & \\
\hline Smart phone & $1.79(1.20: 2.67)$ & $<0.01$ \\
\hline Tablet & $1.84(1.32: 2.57)$ & $<0.001$ \\
\hline Tobacco use & $1.88(1.28: 2.77)$ & 0.001 \\
\hline \multicolumn{3}{|l|}{ Internet time devoted to } \\
\hline Equally work and leisure & Reference category & \\
\hline Mainly leisure & $2.38(1.57: 3.61)$ & $<0.001$ \\
\hline \multicolumn{3}{|l|}{ Online activities on school days } \\
\hline Online games without money & $1.54(1.03: 2.32)$ & $<0.05$ \\
\hline Online gambling & $3.23(1.25: 8.39)$ & $<0.05$ \\
\hline Social networking sites & $1.84(1.04: 3.26)$ & $<0.05$ \\
\hline Participation in online discussions & $2.04(1.43: 2.89)$ & $<0.001$ \\
\hline Other activities & $1.56(1.12: 2.18)$ & $<0.01$ \\
\hline Online encyclopedias & $0.63(0.45: 0.87)$ & $<0.01$ \\
\hline
\end{tabular}

association between problematic Internet use and smoking status, PIUs being more frequently current smokers.

The log-linear model showed that smoking, online gambling, poor emotional well-being, online discussions (i.e., chatting, forums, etc.), online encyclopedia use, as well as access through smartphone and tablet were directly related to problematic Internet use (Fig. 1).

\section{Discussion}

To our knowledge, this study is the first one to determine the characteristics and online activities of problematic and regular Internet users in a large sample of young female students. Overall, $13 \%$ of them were problematic Internet users. This prevalence rate is consistent with those reported on females in other European countries using the same instrument [6].

On school days, PIUs spend a great deal of their online time for leisure activities. Indeed, our results reveal that female PIUs notably stand out in online gambling, online discussions, and social networking sites. The literature indicates that problematic Internet users, particularly females, tend to overuse online applications dedicated to social function, communication, or leisure [1, 29, 37, 28]. Besides, these communication activities and the relational and interactive aspects of social media have been identified as highly addictive among teenagers and young adults, particularly females [13, 31, 24, 40, 37]. The deep immersion in online interactive activities can lead users to lose track of time and stay online longer than intended. Van den Eijnden et al. [40] showed that instant messenger use and chatting positively related to compulsive Internet use 6 months later. In fact, spending frequent online time for leisure-related tasks on school days could have several implications. First, in our study, PIUs are less inclined to be physically active, which could impact on their health status and weight [17]. Spending excessive time online could also interfere with the time usually devoted to other social, academic, or work activities. For example, our study demonstrated that PIUs less frequently use online encyclopedia for study purposes compared to RUs, which, to an extent, could negatively affect their academic performance.

Small portable devices to access the Internet are popular among PIUs. As a matter of fact, the log-linear model shows that smartphones and tablets used to connect to the Internet are directly linked to the use of social networking sites and problematic Internet use. Consistent with our findings, Punamaki et al. [32] attested that intensive mobile phone use is directly associated with intensive computer use among young adolescent girls. Compact devices are easily hidden from parental supervision, and their use can easily become uncontrolled and the Internet accessible at any time. It appears that adolescent girls already outnumber boys in cell phone ownership and use it more intensively and frequently [29]. Smartphones are not merely used to talk [3], but thanks to an almost ubiquitous wireless Internet access, have advanced capabilities very similar to computers [14]. Moreover, computers are more associated with work, whereas portable devices, more straightforward in use, are carried all over the place and used at any time and place. For social purposes, tablets and smartphones fit perfectly. Given that adolescents' daily use of the Internet may serve many purposes simultaneously (i.e., multitasking) [10], it should be considered that their tasks might be undertaken on several devices alternatively $[3,10,12]$. Our data seem to indicate that having access to the Internet through multiple devices is a risk factor for problematic use.

A surprising finding lays in the fact that a sizeable percentage of female PIUs reported online gambling. In fact, engaging in online gambling has been found to be strongly associated with problematic Internet use, but mainly among male users $[41,19,38,18]$. Our result may imply that female PIUs are enlarging their scope of activities to online domains that used to be male-specific. Previous studies have found gender differences in the use of and motives for specific online activities [32, 1, 13, 14, 24]. Whereas young women have a tendency to prefer relational aspects of the Internet, men seem to seek excitement, fun, adventure, exploration, as well as competition and are keen on playing online games, gambling, and reading newspapers $[32,30,25]$. We should remain cautious in the interpretation of this result as the literature highlighting online gambling among adolescent females 


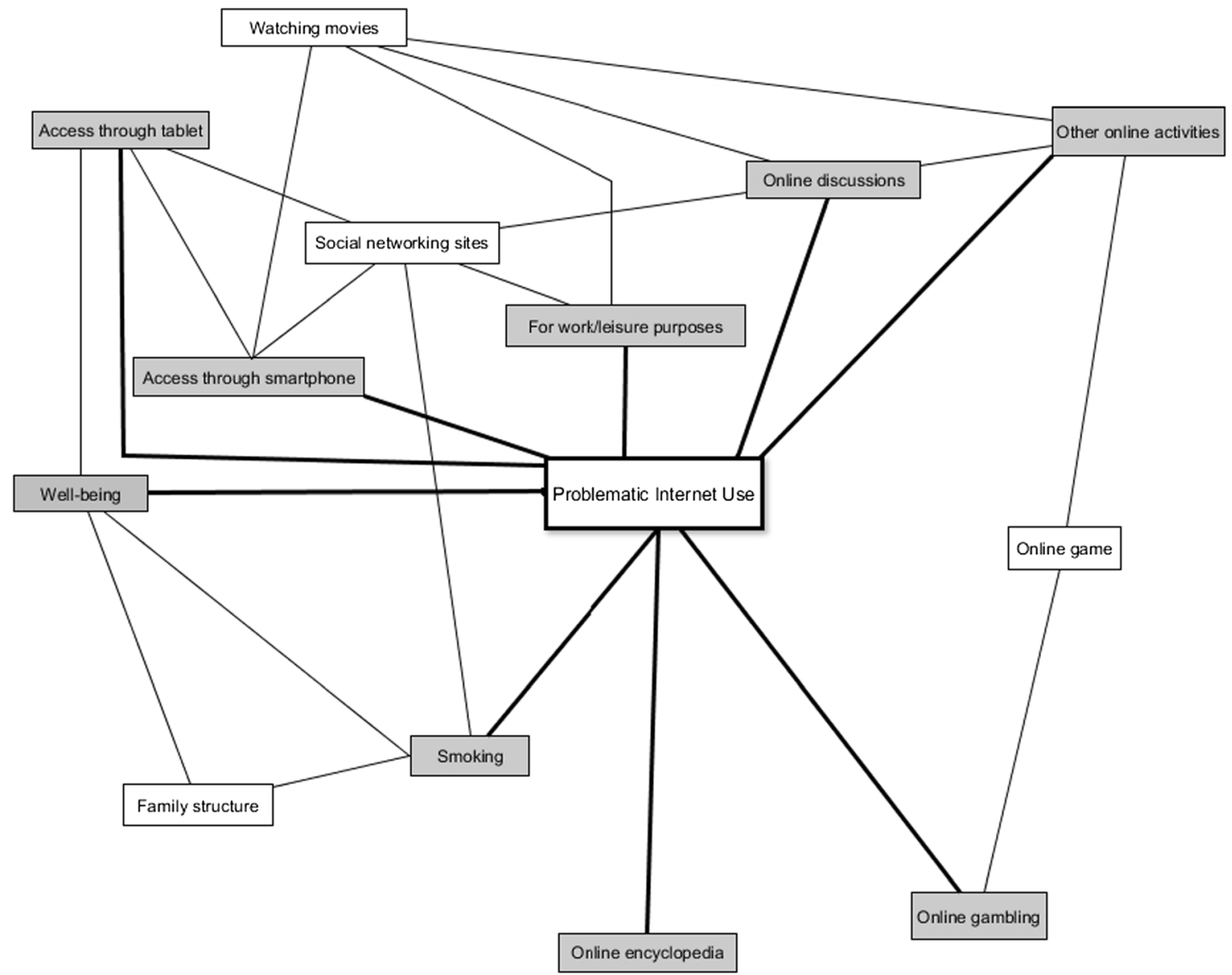

Fig. 1 Log-linear model. Grey boxes indicate a direct link to Problematic Internet Use

is almost inexistent, and future research exploring this finding is needed.

Problematic Internet use has been associated with poor emotional well-being [34, 2, 19, 43] and risk-taking behaviors [23]. Our results support this association, as PIUs are more than 2.5 times more likely to report a poor emotional wellbeing in comparison to RUs. It is suggested that online interactions fail to offer sufficient feelings of support or intimacy provided by face-to-face relationships $[2,8]$. By reducing the time spent with friends or family, excessive use of the Internet in adolescence might negatively impact face-to-face interactions, at the same time as disturbing work and study functions, resulting in reduced adolescent happiness [20].

Additionally, health-compromising behaviors such as cannabis, drug use, or alcohol misuse are found to be positively related to problematic Internet use [7, 26, 22]. This finding could be explained by Jessor's Problem Behavior Theory that postulates the clustering of risk behaviors [11]. Of importance, PIUs in our study are almost twice more at risk to be current smokers than RUs, whereas no salient differences were found among groups related to illegal substance use, cannabis use, or alcohol misuse. These results might partly be explained by their young age and by the fact that smoking is likely to be a gateway to the consumption of other "harder" drugs [15]. Excessive Internet use combined with tobacco use as well as poor emotional well-being among young girls must raise awareness from clinicians and parents, as it could be a gateway to more serious health-compromising behaviors in late adolescence.

The main strengths of this study are the large sample size and the use of a standardized international instrument which enable generalizability and comparison. Additionally, our findings provide relevant perspectives regarding female adolescents' excessive Internet use, by differentiating types (leisure/work) and contexts of use. Yet, some limitations need to be discussed. First, the study's cross-sectional design precludes conclusions about causality. Second, with multitasking being very common among adolescents, the distinction between different online activities might not be as clear-cut as assumed in our study. Third, focusing on online activities on school days exclusively was decided in order to have insights on what occupies female adolescents after school, as this is the time when it can most interfere with their daily routine. However, looking at online activities on weekends could have brought additional highlights. Finally, the use of self-reported measures may limit to a small extent the interpretation of the 
study findings. Nevertheless, since the questionnaire was anonymous, any bias resulting from social desirability is likely to be moderate.

\section{Conclusions}

In conclusion, our findings support that a sizeable percentage of female adolescents are problematic Internet users. Adolescent females' excessive use of the Internet constitutes a new trend which is likely to further increase in the years to come. Thus, clinicians should keep in mind to equally screen young females and males for Internet excessive use when performing a comprehensive biopsychosocial assessment. Teenagers owning numerous devices to access the Internet, presenting other health-compromising behaviors or a poor emotional well-being should be specifically targeted.

Funding The ado@internet.ch study has been financed by the Service of Public Health of the canton of Vaud and by the Swiss National Science Foundation (FNS 105319_140354). The funding bodies had no role in the design and conduct of the study; in the collection, analysis, and interpretation of the data; or in the preparation, review, or approval of the manuscript.

Ethics approval This study was approved by the Ethics Committee of the canton of Vaud.

Ethical responsibilities of authors The manuscript has not been published elsewhere for publication or submitted for consideration.

Conflict of interest The authors declare that they have no conflict of interest.

Authors' contributions Claire Piguet (Claire.piguet@chuv.ch) conceptualized and designed the study; coordinated data collection; acquired, analyzed, and interpreted the data; drafted and revised the manuscript; and approved the final version of the manuscript as submitted. André Berchtold (Andre.Berchtold@unil.ch) conceptualized and designed the study, obtained funding, analyzed and interpreted the data, critically revised the manuscript, and approved the final version of the manuscript as submitted. Christina Akre (Christina.Akre@chuv.ch) conceptualized and designed the study, coordinated data collection, critically revised the manuscript, and approved the final version of the manuscript as submitted. Joan-Carles Surís (joan-carles.suris@chuv.ch) conceptualized and designed the study; obtained funding; acquired, analyzed, and interpreted the data; critically revised the manuscript; and approved the final version of the manuscript as submitted.

\section{References}

1. Barker V (2009) Older adolescents' motivations for social network site use: the influence of gender, group identity, and collective selfesteem. CyberPsychology Behav 12:209-213. doi:10.1089/cpb. 2008.0228
2. Chen S-K (2012) Internet use and psychological well-being among college students: a latent profile approach. Comput Hum Behav 28: 2219-2226. doi:10.1016/j.chb.2012.06.029

3. Cotten SR (2008) Students' technology use and the impacts on wellbeing. New Dir Stud Serv 2008:55-70. doi:10.1002/ss.295

4. de Wit M, Pouwer F, Gemke RJBJ, Delemarre-van de Waal HA, Snoek FJ (2007) Validation of the WHO-5 Well-Being Index in adolescents with type 1 diabetes. Diabetes Care 30:2003-2006. doi:10. 2337/dc07-0447

5. Derbyshire KL, Lust KA, Schreiber LR, Odlaug BL, Christenson GA, Golden DJ, Grant JE (2013) Problematic Internet use and associated risks in a college sample. Compr Psychiatry 54:415-422. doi: 10.1016/j.comppsych.2012.11.003

6. Durkee T, Kaess M, Carli V, Parzer P, Wasserman C, Floderus B, Apter A, Balazs J, Barzilay S, Bobes J, Brunner R, Corcoran P, Cosman D, Cotter P, Despalins R, Graber N, Guillemin F, Haring C, Kahn JP, Mandelli L, Marusic D, Meszaros G, Musa GJ, Postuvan V, Resch F, Saiz PA, Sisask M, Varnik A, Sarchiapone M, Hoven CW, Wasserman D (2012) Prevalence of pathological Internet use among adolescents in Europe: demographic and social factors. Addiction 107:2210-2222. doi:10.1111/j.1360-0443.2012.03946.x

7. Frangos CC, Frangos CC, Sotiropoulos I (2011) Problematic Internet use among Greek university students: an ordinal logistic regression with risk factors of negative psychological beliefs, pornographic sites, and online games. Cyberpsychol Behav Soc Netw 14:51-58. doi:10.1089/cyber.2009.0306

8. Green MC, Hilken J, Friedman H, Grossman K, Gasiewskj J, Adler R, Sabini J (2005) Communication via instant messenger: short- and long-term effects. J Appl Soc Psychol 35:445-462. doi:10.1111/j. 1559-1816.2005.tb02130.x

9. Guan S-SA, Subrahmanyam K (2009) Youth Internet use: risks and opportunities. Curr Opin Psychiatry 22:351-356

10. Jeong S-H, Fishbein M (2007) Predictors of multitasking with media: media factors and audience factors. Med Psychol 10:364-384. doi: 10.1080/15213260701532948

11. Jessor R (1987) Problem-behavior theory, psychosocial development, and adolescent problem drinking. Br J Addict 82:331-342

12. Judd T (2014) Making sense of multitasking: the role of Facebook. Comput Educ 70:194-202. doi:10.1016/j.compedu.2013.08.013

13. Junco R (2013) Inequalities in Facebook use. Comput Hum Behav 29:2328-2336. doi:10.1016/j.chb.2013.05.005

14. Junco R, Merson D, Salter DW (2010) The effect of gender, ethnicity, and income on college students' use of communication technologies. Cyberpsychol Behav Soc Netw 13:619-627. doi:10.1089/cyber. 2009.0357

15. Kandel DB, Yamaguchi K, Klein LC (2006) Testing the gateway hypothesis. Addiction 101:470-472. doi:10.1111/j.1360-0443.2006. 01426.X

16. Khazaal Y, Billieux J, Thorens G, Khan R, Louati Y, Scarlatti E, Theintz F, Lederrey J, Van Der Linden M, Zullino D (2008) French validation of the Internet addiction test. Cyberpsychol Behav 11:703706. doi:10.1089/cpb.2007.0249

17. Kim JH, Lau CH, Cheuk K-K, Kan P, Hui HLC, Griffiths SM (2010) Brief report: predictors of heavy Internet use and associations with health-promoting and health risk behaviors among Hong Kong university students. J Adolesc 33:215-220. doi:10.1016/j.adolescence. 2009.03.012

18. Kormas G, Critselis E, Janikian M, Kafetzis D, Tsitsika A (2011) Risk factors and psychosocial characteristics of potential problematic and problematic Internet use among adolescents: a cross-sectional study. BMC Public Health 11:595. doi:10.1186/1471-2458-11-595

19. Kraut R, Kiesler S, Boneva B, Cummings J, Helgeson V, Crawford A (2002) Internet paradox revisited. J Soc Issues 58:49-74. doi:10. $1111 / 1540-4560.00248$

20. Kraut R, Patterson M, Lundmark V, Kiesler S, Mukopadhyay T, Scherlis W (1998) Internet paradox. A social technology that reduces 
social involvement and psychological well-being? Am Psychol 53: 1017-1031

21. Kuss DJ (2013) Internet gaming addiction: current perspectives. Psychol Res Behav Manag 6:125-137. doi:10.2147/PRBM.S39476

22. Kuss DJ, Griffiths MD (2011) Online social networking and addiction-a review of the psychological literature. Int $\mathrm{J}$ Environ Res Public Health 8:3528-3552

23. Kuss DJ, Griffiths MD (2012) Internet and gaming addiction: a systematic literature review of neuroimaging studies. Brain Sci 2:347374

24. Kuss DJ, Griffiths MD, Binder JF (2013) Internet addiction in students: prevalence and risk factors. Comput Hum Behav 29:959-966. doi:10.1016/j.chb.2012.12.024

25. Lai C-H, Gwung H-L (2013) The effect of gender and Internet usage on physical and cyber interpersonal relationships. Comp Educ 69: 303-309. doi:10.1016/j.compedu.2013.07.009

26. Lam LT, Peng ZW, Mai JC, Jing J (2009) Factors associated with Internet addiction among adolescents. Cyberpsychol Behav 12:551555. doi: $10.1089 / \mathrm{cpb} .2009 .0036$

27. Leung L (2004) Net-generation attributes and seductive properties of the Internet as predictors of online activities and Internet addiction. CyberPsychology Behav 7:333-348. doi:10.1089/ 1094931041291303

28. Li S-M, Chung T-M (2006) Internet function and Internet addictive behavior. Comput Hum Behav 22:1067-1071. doi:10.1016/j.chb. 2004.03.030

29. Muscanell NL, Guadagno RE (2012) Make new friends or keep the old: gender and personality differences in social networking use. Comput Hum Behav 28:107-112. doi:10.1016/j.chb.2011.08.016

30. Potenza M, Maciejewski P, Mazure C (2006) A gender-based examination of past-year recreational gamblers. J Gambl Stud 22:41-64. doi:10.1007/s10899-005-9002-4

31. Pujazon-Zazik M, Park MJ (2010) To tweet, or not to tweet: gender differences and potential positive and negative health outcomes of adolescents' social Internet use. Am J Mens Health 4:77-85. doi:10. $1177 / 1557988309360819$

32. Punamaki RL, Wallenius M, Nygard CH, Saarni L, Rimpela A (2007) Use of information and communication technology (ICT) and perceived health in adolescence: the role of sleeping habits and waking-time tiredness. J Adolesc 30:569-585. doi:10.1016/j. adolescence.2006.07.004

33. Shaw LH, Gant LM (2002) Users divided? Exploring the gender gap in Internet use. CyberPsychology Behav 5:517-527. doi:10.1089/ 109493102321018150

34. Shaw M, Black D (2008) Internet addiction. CNS Drugs 22:353-365. doi:10.2165/00023210-200822050-00001

35. Sinkkonen H-M, Puhakka H, Meril, auml, inen M (2014) Internet use and addiction among Finnish adolescents (15-19 years), vol 37. vol 2.

36. Sinkkonen HM, Puhakka H, Merilainen M (2014) Internet use and addiction among Finnish adolescents (15-19 years). J Adolesc 37: 123-131. doi:10.1016/j.adolescence.2013.11.008

37. Thatcher A, Wretschko G, Fridjhon P (2008) Online flow experiences, problematic Internet use and Internet procrastination. Comput Hum Behav 24:2236-2254. doi:10.1016/j.chb.2007.10.008

38. Tsitsika A, Critselis E, Janikian M, Kormas G, Kafetzis D (2011) Association between Internet gambling and problematic Internet use among adolescents. J Gambl Stud 27:389-400. doi:10.1007/ s10899-010-9223-z

39. Tsitsika AK, Tzavela EC, Janikian M, K Ó, Iordache A, Schoenmakers TM, Tzavara C, Richardson C (2014) Online social networking in adolescence: patterns of use in six European countries and links with psychosocial functioning. J Adolesc Health. doi:10. 1016/j.jadohealth.2013.11.010

40. van den Eijnden RJ, Meerkerk GJ, Vermulst AA, Spijkerman R, Engels RC (2008) Online communication, compulsive Internet use, and psychosocial well-being among adolescents: a longitudinal study. Dev Psychol 44:655-665

41. van Rooij AJ, Schoenmakers TM, van de Eijnden RJJM, van de Mheen D (2010) Compulsive Internet use: the role of online gaming and other Internet applications. J Adolesc Health 47:51-57. doi:10. 1016/j.jadohealth.2009.12.021

42. Xu J, L-x S, Yan C-h HH, Yang F, Wang L, Kotha SR, L-n Z, X-p L, Zhang J, F-x O, J-s Z, X-m S (2012) Personal characteristics related to the risk of adolescent Internet addiction: a survey in Shanghai, China. BMC Public Health 12:1106

43. Yoo Y-S, Cho O-H, Cha K-S (2013) Associations between overuse of the Internet and mental health in adolescents. Nurs Health Sci. doi:10. 1111/nhs. 12086 